\title{
Mujeres musulmanas: estereotipos occidentales versus realidad social ${ }^{1}$
}

\section{Djaouida Moualhi}

Universitat Autònoma de Barcelona. Departament d'Antropologia Social i de Prehistòria 08193 Bellaterra (Barcelona). Spain

\section{Resumen}

En este artículo, a partir de fuentes bibliográficas y observación no participada, rebato diversas imágenes estereotipadas sobre la discriminación de las mujeres árabo-musulmanas que encuentran amplio eco en Occidente. Primero identifico algunos tópicos acerca de la supuesta discriminación de las musulmanas en general — y atribuidos también a las magrebíes - y los confronto con los hechos para desmentir aquéllos que lo merecen, y determinar hasta qué punto otros tienen una base real. Para ello, a continuación argumento que, en los países magrebíes, en relación con la discriminación de género son más relevantes otros factores que, de hecho, son importantes impulsores de la emigración femenina hacia Occidente y hacia España en particular.

\section{Abstract. Muslim women: Western stereotypes versus social reality}

In this article I refute several stereotyped images about the supposed discrimination of Arabic-Muslim women which are widespread in the West. Firstly, I identify some topics about the supposed discrimination of Muslim women in general, which are also attributed to Magrib women, and I compare them with facts in order to contradict those that are wrong and to grasp to what extent other beliefs have a real foundation. With this aim, then I argue that other factors are more relevant for gender discrimination in Magrib countries, which are actually important causes of female emigration to Spain.

\author{
Sumario \\ 1. Contextualización: estereotipos \\ sobre el mundo musulmán \\ 2. La construcción de la discriminación \\ desde España
}

1. Agradezco a Natalia Ribas su concienzuda labor de editora proporcionándome numerosas sugerencias. También debo un merecido reconocimiento a Enric Martínez Herrera por sus muchos consejos y constante aliento. La investigación de la que es producto ha sido posible en gran parte gracias a la Fundación Jaume Bofill, que me concedió una beca salario predoctoral y otra de complemento durante los cursos 1996/97 y 1997/98. 
La presencia de la inmigración no comunitaria musulmana —árabe, africana, pero sobre todo magrebí-, pues es el colectivo más numeroso en España, concita atención y preocupación social, periodística y científica, prestándose a diversos discursos que van desde el paternalismo hasta la xenofobia. Generalmente se considera el colectivo musulmán como no asimilable, resistente a una disolución en la cultura de la sociedad de acogida, debido a la percepción de una acumulación de diferencias culturales y, especialmente, a la sensación de que las referencias ético-religiosas son insalvables. Paradójicamente, al mismo tiempo es percibido como un colectivo débil, por su frágil situación económica y jurídica en el país receptor, y por suponerle un bagaje previo de hambre, represión e incluso guerra (en el caso de Argelia).

Un lugar común de esos discursos es la situación cultural, económica, familiar y jurídica de las mujeres magrebíes en sus sociedades de origen. En ellos se las describe como marginadas y explotadas por los varones de su propio colectivo. Sin embargo, se pasa por alto que con esta actitud la sociedad receptora alimenta la reproducción de esas mismas situaciones u otras semejantes (Lütz, 1991). El discurso compasivo que las representa como pasivas, sumisas e ignorantes tiene un curioso correlato en el escaso espacio laboral, legal e intelectual en que esta sociedad las encierra. Quizá fuera de más ayuda observarlas como sujetos activos e inteligentes que se esfuerzan por dejar atrás la marginación y la precariedad e intentan compaginar lo mejor de ambas culturas: la de origen y la dominante en la sociedad de acogida.

Como mujer magrebí, musulmana y migrada que soy, el hecho de que todavía campen por sus respetos en la opinión pública, los medios de comunicación e incluso la comunidad científica social de España sorprendentes tópicos acerca de la situación de las mujeres árabo-musulmanas o magrebíes, me hizo ver la necesidad de lidiar con ellos. Muchos de los argumentos que esgrimo no son nuevos en absoluto, pero la colosal inercia, capacidad de resistencia y tenacidad de los estereotipos requiere mucha perseverancia. Las barreras a la autonomía de las mujeres magrebíes en España se cimientan también en ellos. Para la identificación de los tópicos me baso sobre fuentes bibliográficas, artículos de prensa, entrevistas en profundidad y observación no participante (Moualhi, 1997).

\section{Contextualización: estereotipos sobre el mundo musulmán}

Cuando en Occidente se habla de la supuesta discriminación de las mujeres magrebíes se da por sentado que su religión es el origen de sus males, en vez de buscar las causas en la política de los Estados correspondientes y la herencia sociocultural patriarcal de sus sociedades. Para entender esa percepción es importante situarla en el marco general de los estereotipos sobre el mundo islámico, sondeando su procedencia en antecedentes históricos y políticos. $\mathrm{Al}$ fin y al cabo, la hostilidad y xenofobia exhibidos actualmente hacia los musulmanes encuentran parte de su alimento en rancios tópicos sobre el islam.

En España, los periodistas, la intelligentsia en general, e incluso algunos científicos sociales, incurren fácilmente en el etnocentrismo en cuanto alu- 
den a la situación de las musulmanas. Una característica importante de esa perspectiva es la asunción como axioma de una diferencia entre Oriente y Occidente, oponiendo la racionalidad de «nosotros» a la irracionalidad de «ellos», y «nuestro» desarrollo con «su» subdesarrollo, con lo que se reafirma la propia identidad entendida como superior. Una gran parte de los periodistas continúa viendo a estas mujeres como víctimas dependientes en un estado de semiesclavitud, culpando de ello a la religión musulmana. Los medios de comunicación propagan imágenes deformadas y estereotipadas sobre el velo, la clitoridectomía y la violencia política en países musulmanes; en una economía del discurso que ha medrado aún más con la violencia que desarrollan algunos miembros de los movimientos integristas islámicos ${ }^{2}$. La discriminación de las afganas y el secuestro y asesinato de algunas argelinas llegan a la opinión pública de manera distorsionada y amplificada. Naturalmente, estas imágenes despiertan sentimientos de sospecha, recelo y temor, al tiempo que refuerzan juicios previos sobre los musulmanes como violentos, agresivos y misóginos ${ }^{3}$.

Los apriorismos se extienden también a las ciencias sociales. Como señala Ramírez (1995: 145; 1998: 50-51), en algunas investigaciones sobre inmigración femenina magrebí aparece una islamización del objeto de estudio, ya que en ellas se atribuye las relaciones de dominación entre géneros al islam, al partir del axioma de que esta religión discrimina a las mujeres.

Los estereotipos occidentales sobre las sociedades musulmanas como misóginas, fanáticas, irracionales y violentas no son nuevos. El islam era (y sigue siendo) visto como una amenaza para la moral cristiana. Según Robinson (1990: 16), entre los siglos XII y XVIII, la Iglesia hizo hincapié en un ataque a Mahoma. Su vida se convirtió en el centro de atención para tratar de demostrar que era un falso profeta y la irracionalidad y la agresividad de la religión musulmana. Entre otros cargos, le acusaban de inmoralidad por aconsejar a su pueblo que gozase de su sexualidad (aunque esta recomendación se sitúa dentro del matrimonio).

En la visión etnocéntrica se manifiesta un miedo a lo distinto, percibido como extraño y peligroso. En el terreno de la sexualidad, el discurso cristiano hegemónico ve a su religión como verdadera y a la del otro como equivocada e inmoral. Al mismo tiempo que el islam legitima la poligamia y el matrimonio entre primos de primer grado, el cristianismo prohibe la primera y desaconsejaba hasta hace poco el segundo, que requería del consentimiento de las autoridades religiosas ${ }^{4}$.

2. Santamaría señala la presencia en algunos medios de comunicación españoles de una visión caricaturizada del inmigrante extracomunitario musulmán (1993). Véase también el análisis del tratamiento que recibe el islam en los manuales escolares españoles en Navarro (1997).

3. Véanse algunos ejemplos en los periódicos El Pais, 14/9/94: 10; 30/12/94: 3; 9/2/95: 10; 1/11/95: 10; y el Mundo 13/3/95.

4. Un ejemplo actual lo aporta Manyer, cuando critica la concepción islámica del matrimonio oponiéndola a la cristiana (1997: 62). 
Otra acusación hacia Mahoma fue que había pretendido extender su religión por la fuerza. Se criticaba la violencia en las guerras santas musulmanas, aunque, obviamente, los cristianos también derramaban sangre cuando libraban guerras santas (véase Maalouf, 1994). Puede considerarse que la imagen negativa que tacha a los árabes y/o musulmanes de fanáticos violentos tiene su origen en este discurso de la época de las cruzadas (Robinson, 1990: 18).

La asociación entre las ideas "musulmán» y "fanatismo» sigue presente a comienzos del siglo XIX, cuando la mayoría de los países árabes y musulmanes es colonizada por potencias occidentales. La principal arma ideológica de unos musulmanes debilitados por conflictos internos era el islam, que proporcionaba una identidad común frente a invasores con distinta religión (volveré a hablar sobre este tema más adelante). Los occidentales, por su parte, recurrían a la ridiculización y demonización de aquéllos, presentándolos como primitivos, irracionales y violentos 5 . Obviamente, ésta fue una estrategia para legitimar su empresa colonizadora.

Durante la colonización se forjo un nuevo tópico: el de la misoginia. Interpretada por los colonizadores, la situación de las mujeres sirvió para argumentar la inferioridad del islam, su «falta de normalidad» (Fanon, 1972; RamziAbadir, 1986; Jansen, 1989). Acompañando la dominación francesa de la mayor parte del Magreb, apareció una literatura claramente etnocéntrica, que hoy haría sonrojar a más de uno, arguyendo la superioridad de su civilización frente a la árabo-musulmana (véanse infra la sección sobre el velo y la herencia).

Como han argumentado diversos autores (Fanon, 1972; Jansen, 1987; Mateo, 1997), existe una relación histórica entre el poder y la prepotencia coloniales y la producción de un imaginario que legitima esa dominación evitando aludir a los intereses materiales. De hecho, el incremento actual de los prejuicios xenófobos hacia la inmigración procedente del Magreb en España y el resto de Europa sugiere un sospechoso paralelismo con la construcción de las fronteras de la Unión Europea en una coyuntura económica de menor necesidad de mano de obra (Stolcke, 1994). Asimismo, como sostiene Said (1995: 3), una de las principales bases de la construcción de una unión cultural e identitaria europea es la oposición y diferenciación respecto de Oriente.

Además de las imágenes negativas existen también otras de una cierta mitificación, un imaginario «romántico» que atribuye a las sociedades árabo-musulmanas un atractivo exótico (Robinson, 1990 y Said, 1995). La postura idealista permite a algunos occidentales alcanzar sus ilusiones, ya sea en sus fantasías o en aventuras escogidas a la carta. Los numerosos ejemplos incluyen desde obras del compositor Mozart y los filósofos Montesquieu y Goethe hasta las aventuras de Lawrence de Arabia. Asimismo, en un siglo XIX europeo puritano, hubo quien soñó con una mayor libertad sexual, en el mundo fantástico y sen-

5. Una exposición de cómo se ha ido construyendo la imagen del moro, en el caso de protectorado español en Marruecos, puede verse en Mateo (1997). Otros ejemplos sobre la literatura y el arte occidental pueden verse en Robinson (1990). 
sual de los placeres y la voluptuosidad del harén relatado por Las mil y una noches, como los pintores Renoir y Delacroix (Robinson, 1990: 18-19; Djebar, 1992: 140-141). En el siglo XX, los estereotipos, tanto negativos como positivos, se manifiestan todavía en todas las artes populares: literatura, artes plásticas, cinematografía, música y cómic ${ }^{6}$.

\section{La construcción de la discriminación desde España}

Los estereotipos aducidos más frecuentemente en relación con la discriminación de las musulmanas son el velo, el sistema de herencia, la clitoridectomía y la poligamia. Para superar la visión etnocéntrica, en esta parte demuestro que aunque estas prácticas existen, no son generalizables, y que mientras algunas están prescritas en el Corán, otras son costumbres preislámicas que siguen en uso sólo en algunas sociedades, tanto de fe musulmana como de fe cristiana. Asimismo compruebo qué dice el Corán acerca de ellas a fin de evaluar si son o no imputables a la esencia del islam.

\subsection{La clitoridectomía}

Frecuentemente leemos, escuchamos o vemos imágenes distorsionadas, falsas, o aisladas del contexto social que puede darles sentido, para demostrar la opresión de las musulmanas. No es raro encontrar un artículo de prensa en el que la ablación del clítoris aparece como una «costumbre de origen africano basada en los principios de la religión islámica» ${ }^{7}$. Lo cual es rotundamente falso.

La circuncisión en general, tanto masculina como femenina, es una práctica antiquísima, anterior a la edad del bronce. Heredoto ya mencionó la femenina en el siglo $\mathrm{V}$ antes de Cristo, practicada por egipcios, hititas, fenicios, etíopes y griegos (Lerner, 1990: 282). Esta mutilación ha ido tomando diferentes formas (infibulación, introcisión) en distintos pueblos (sudaneses, conibos del Perú, australianos). Los motivos son diversos: algunos pueblos por higiene y como preparación a la vida sexual, otros como sacrificio (símbolo religioso de purificación) o como una marca de distinción, o ambos al tiempo (Mujeres en acción, 1993: 2; Dorkendoo y Elworthy, 1994: 12-14).

En las sociedades árabo-musulmanas, se sigue realizando la circuncisión masculina y, en mucho menor medida, la escisión femenina. Ambas simbolizan el ingreso en la comunidad (Bouhdiba, 1986: 214). Aunque la masculina

6. Algunos de estos ejemplos se encuentran en los cómics, por ejemplo, en «Las aventuras de Tintín» (que presenta a los árabes por un lado como unos «buenos» algo tontos o como «malos» traicioneros, en Stock de Coke y Los cigarros del Faraón), "Corto Maltés» y «El Guerrero del antifaz». En el cine se puede mencionar la película No sin mi hija. En cuanto a las canciones, llama la atención Quitame el velo del conjunto Amistades Peligrosas, clarísima simplificación etnocéntrica de la situación de la musulmana, que ha gozado de gran difusión en los medios de comunicación.

7. R.M. TRISTÁN, «Egipto autoriza la ablación del clítoris en hospitales públicos», El Mundo, 3/3/1995: 56 (la cursiva es mía). 
es la más generalizada, no existe ningún versículo en el Corán que la mencione, y tan sólo algún dudoso hadiz (hecho o dicho atribuido a Mahoma y sus compañeros) parece mencionar la circuncisión de Mahoma ${ }^{8}$. Por su parte, la circuncisión femenina ni siquiera es aludida en los hadices, aunque, si acaso, según un hadiz citado por Bouhdiba, parece que Mahoma, al ser preguntado sobre este tema, mostró reticencia (1986: 216). Así pues, es una práctica tan poco musulmana como cristiana. Una práctica preislámica que sigue presente tan sólo en algunos países musulmanes, pero no en los del Magreb. Y que en cambio sí lo está también entre muchos cristianos de Egipto, Sudán y el Âfrica Subsahariana (Dorkendoo y Elworthy, 1994: 22 y 23).

\subsection{La poligamia}

Otra de las cuestiones que más atención concitan es la de la poligamia (técnicamente, poliginia). Son varias las consecuencias de la crítica que algunos occidentales le dirigen. Es más, convirtiendo a «los otros» en unos pecadores o, actualmente, en unos tiranos antidemocráticos, esos occidentales parecen pretender reafirmar su identidad monógama. Primeramente, al oponer la monogamia a la poligamia, las formas matrimoniales sirven para identificar y diferenciar los propios de los extraños para construir la identidad occidental. Y segundo, se convierte a los musulmanes en un todo homogéneo donde la poligamia deviene la regla general.

Es cierto que el Corán la permite, pero en ningún caso resulta obligatoria. Si nos adentramos en el libro sagrado musulmán notamos que la poligamia es desaconsejada, ya que, en caso de practicarla, el hombre debe ser equitativo con sus esposas, tanto en el trato sentimental o afectivo como en los aspectos materiales (Sura IV, Aleya 128). Si se exige justicia y rectitud, que son difíciles de realizar, lo aconsejado es el matrimonio monógamo. Por otra parte, el hombre no puede contraer matrimonio con una segunda esposa sin que la primera lo apruebe. Otra cosa es que en la práctica suela conculcarse el derecho de la mujer a oponerse a un nuevo matrimonio de su cónyuge.

En cualquier caso, pasando de lo normativo a lo efectivo, se observa que la incidencia de la poligamia es muy desigual, variando considerablemente de un ámbito social a otro. En primer lugar, en el Magreb, los ámbitos rurales suelen ser más reacios a la práctica de la poligamia, debido quizá a que en ellos las mujeres no están recluidas y a que, al trabajar en el campo, tienen más fácil el regreso a la familia paterna en caso de quiebra matrimonial ${ }^{9}$. Otra explica-

8. Entre los judíos la circuncisión masculina, prescrita en la Torá, tiene un significado religioso de purificación. Se efectúa en una edad muy temprana (al nacer un bebé o después de algunos meses) y es acompañada de un acto religioso. Los musulmanes la adoptaron de ellos, pero fijando su realización entre los seis y doce años y sin ceremonia religiosa.

9. Esta explicación puede no tener ningún sentido, si hablamos de países de Oriente Medio. Un informante sirio me explicó que en su país la incidencia de la poligamia es más alta en los medios rurales que en los urbanos porque en su país las mujeres suelen ocuparse de la 
ción más plausible es que los hombres se conforman con una sola esposa por los costes que supone contraer matrimonio con una segunda (véanse Bouhdiba, 1986 y Mernissi, 1995).

En segundo lugar, esta práctica también varía de unos países a otros. La tasa más elevada de poligamia se ubica en países del mar Rojo como son Arabia Saudí (por cada mil varones casados, 120 son polígamos) y Sudán (168 por millar). En cambio, en los países del Magreb la tasa de poligamia es de las más bajas (18 por millar en Argelia), con la excepción de Marruecos (66 por millar). En Túnez está prohibida desde 1956 (aunque, naturalmente, sin efectos retroactivos) (Manyer, 1996). En términos generales podemos concluir que hay una gran variabilidad en la incidencia de esta práctica en los países musulmanes.

Asimismo, considerando la situación económica actual y el cambio de mentalidad de las nuevas generaciones, pocos hombres hoy la desean y, además, el acceso de las mujeres al mercado laboral y la educación disminuye su tolerancia ante tales pretensiones. Por lo tanto, la creencia etnocéntrica sobre la poligamia se apoya en una inducción lógicamente falsa: han creado afirmaciones universales a partir de casos particulares (falacia pars pro toto).

\subsection{El discurso occidental sobre el velo y las reglas de la herencia}

El velo y la herencia fueron instrumentalizados durante el periodo colonial para justificar la sujeción política, económica y cultural por potencias occidentales de sociedades de mayoría musulmana y todavía tienen eco en la opinión pública occidental. Algunos franceses crearon el discurso del velo durante la colonización de Argelia. Con él procuraban, de un lado, persuadir a la metrópoli de la inferioridad del islam para legitimar su empresa bajo la piel de cordero civilizadora y, por otro lado, debilitar la resistencia argelina poniendo en su contra a parte de las mujeres colonizadas, al exponerles que el velo era un claro síntoma de su discriminación (Fanon, 1972; Ramzi-Abadir, 1986; Jansen, 1989).

Este discurso colonial se yuxtaponía a otro discurso, todavía vivo, sobre la campesina cabileña argelina, que no suele emplear velo, presentada idealmente como una mujer libre e independiente (Jansen, 1989). Siguiendo la máxima «divide y vencerás», esta diferenciación entre la árabo-argelina (con estatus inferior) y la beréber-argelina (con estatus superior) no era más que una hábil estrategia para dividir y debilitar al pueblo colonizado, integrada perfectamente en la política más amplia de destacar las diferencias entre las etnias beréberes y árabes que los franceses implementaron tanto en Argelia como en Marruecos y Túnez.

mayor parte del trabajo del campo. Así, para un hombre cada mujer que desposa representa una fuerza de trabajo. Según otro informante, inmigrado marroquí, en algunas zonas rurales de su país sucedería lo mismo, concretamente en el Rif (Moualhi, en preparación; véase también Ribas, 1996). 
En general, cuando se habla del velo se pretende que es una evidencia de la discriminación y la sumisión de la desvalida musulmana. Así hay quien afirma: "Una de las obligaciones indisolubles de la [...] musulmana es el hijab (velo), símbolo por excelencia de la marginación y de la alienación a que ha sido sometida por su religión" (Manyer, 1996: 67; cursivas y traducción mías). Es decir, al definir la situación de las musulmanas se da implícitamente por supuesto que el islam es su enemigo, degrada su dignidad y las somete a un nivel infrahumano. Mas lo cierto es que para las magrebíes el velo nunca ha representado un obstáculo en su camino de emancipación (Mernissi, 1987; Taarji, 1991; Bessis y Belhassen, 1992). Como el pañuelo o la mantilla en otras latitudes (tan frecuente en el Mediterráneo), existe desde hace muchos siglos en el Magreb, con los nombres de hayek, yelaba o melaya y hijab ${ }^{10}$. No hace mucho, las mujeres se cubrían con él como signo de elegancia, como hacían las antiguas griegas y romanas, y todavía puede verse en la alta costura parisina.

Actualmente su utilización corresponde con frecuencia a convicciones personales de índole ética, puesto que está prescrito en el Corán, de suerte que para quienes lo visten no representa un acto de sumisión a los hombres, sino una expresión voluntaria de su fe y su sumisión a Dios. También ha ocurrido que el movimiento independentista argelino contrapuso al discurso colonizador francés el uso del velo como símbolo de identidad musulmana frente al invasor, de tal suerte que muchas activistas argelinas lo llevaban con fines políticos. El uso que actualmente hacen algunas jóvenes francesas de origen magrebí quizá vaya también en esta dirección, como reivindicación de una identidad social diferenciada. No es menos cierto, sin embargo, que cediendo a las presiones sociales del entorno, otras lo llevan para no ser prejuzgadas ni ser molestadas en lugares públicos, y en otros casos por imposición familiar. Aunque para éstas sí es un síntoma de discriminación y falta de libertad y, en este sentido, el tópico tiene base real, hay que insistir en que la razón para llevarlo es generalmente bien distinta: una profunda convicción religiosa.

Estos últimos años son las mujeres con hijab, un nuevo perfil de la mujer que se quiere «ocultar», "velar», las que irrumpen en el espacio público y reivindican así su identidad como musulmanas. Velarse es para ellas una orden

10. El hayek es una típica capa de seda, generalmente de color blanco o beige y sin ninguna costura, que solían llevar tradicionalmente las mujeres magrebíes (y aún lo llevan muchas sobre todo en Argelia). La melaya o jelaba es tradicionalmente de tela gruesa, dependiendo su color de las regiones. A diferencia del hayek, esta prenda es cosida, con mangas, y puede llevar capucha. Actualmente, en el Magreb y en la mayor parte de los países musulmanes, muchas mujeres bajo la presión de los islamistas y otras por elección propia han cambiado estas prendas tradicionales por el llamado hijab o por el chador. Hijab quiere decir en árabe 'velo que cubre la cabeza', y viene del verbo hajaba que significa, 'esconder', 'velar', y también 'cortina'. La mutahajiba es la mujer que lleva el velo o la que está recluida. El hijab es un pañuelo que cubre la cabeza y puede ser de diferentes colores, llevarse con cualquier vestido, falda o pantalón amplio que no muestre las formas, y se suele llevar en el Magreb y países de Oriente. En cambio, el chador es una prenda única cosida y que cubre todo el cuerpo incluyendo la cabeza y debe ser de color negro, típica de Irán y ajena a las tradiciones norteafricanas. 
divina, una necesidad que se sigue de su creencia. Asimismo, el velo simboliza un orden social basado en la dicotomía sexual. El velo, más que su función utilitaria, tiene una función ética. Por pudor éste no tiene que realzar su cuerpo sino disimularlo (véanse Taarji, 1991; Bessis y Belhassen, 1992).

Según Manyer, la utilización del velo como signo de identidad y pertenencia a la cultura islámica conlleva en sí una oposición a las «otras» (occidentales desveladas), consideradas como mujeres sin pudor. Incluso puede ser una expresión de xenofobia, de rechazo a lo diferente, como posiblemente ocurra entre algunas mujeres integristas islámicas (Manyer, 1996: 67). En este sentido, el velo o hijab adquiere una connotación política, como la tuvo durante la lucha anticolonial. Como hemos visto anteriormente, durante la colonización francesa en Argelia, el velo fue instrumentalizado por discursos enfrentados. La administración colonial intentaba poner a las mujeres en contra de los hombres convenciéndolas de que el velo era un síntoma de su discriminación para así debilitar la resistencia. En contraposición, los colonizados incitaban a sus mujeres a llevar el velo como resistencia a la aculturación y como símbolo de la identidad árabo-musulmana. Así el velo devenía en aquella época la manifestación de un nacionalismo que rechaza la asimilación al modelo occidental, un medio para distinguirse del colonizador. En efecto, como afirma Fanon (1975: 16), «les techniques vestimentaires, les traditions d'habillement, de parement, constituent les formes d'originalité les plus marquantes, c'est-à-dire les plus immédiatement perceptibles d'une société».

Por cierto que últimamente en España ha producido cierta preocupación entre los enseñantes el uso del velo por algunas de sus alumnas. Eran ecos procedentes de la vecina Francia, donde el velo fue recibido con bastante alarma, así como reacciones dudosas, como la de la dirección de un colegio que expulsó a dos estudiantes del centro por vestirlo. Lo paradójico es que se argumente que es una evidencia de falta de libertad, cuando en las sociedades occidentales la presión social es más bien en contra del velo. En sociedades donde se proclama la libertad de culto y en el vestir, esa prenda no tendría que ser vista más que como un signo inocente del ejercicio de esos derechos, comparable al corriente colgante en forma de crucifijo.

Otro importante foco de atención reside en el régimen de herencia. Si se contempla superficialmente el sistema de herencia prescrito por el Corán parece favorecer al hombre, pero no es legítimo descontextualizar ese aspecto particular del más amplio sistema social en el que se inscribe. Si bien el Corán establece que debe darse a los varones el doble que a las mujeres (Sura IV, Aleya 11), también prescribe que ellos deben sustentar a la esposa e hijos, mientras que los bienes de las mujeres, trabajen o no, les pertenecen únicamente a ellas, quienes no deben sustentar a nadie. Es más, si el marido quisiera utilizarlos, debería obtener el permiso de su esposa. En realidad, la clave es la lógica de distribución de papeles dentro de la familia, e incluso podría argüirse que en este aspecto la mujer dispone de un cierto trato de favor. Mientras se mantenga la estructura familiar tradicional, el actual régimen de herencia no resulta injusto. Cosa bien distinta sería conservarlo con una organización fami- 
liar en la cual la mujer tenga un papel productivo o si se utiliza como un método para hacerla dependiente.

$\mathrm{Al}$ mostrar la falsedad de estos tópicos no pretendo afirmar que las magrebíes no estén discriminadas en su país de origen, sino que las imágenes divulgadas son a menudo distorsionadas y/o equivocadas. Se basan sobre hechos particulares o superficiales para después llevar a cabo afirmaciones generales o de mayor calado. Las magrebíes no están discriminadas por llevar velo cuando lo hacen por convicción, ni por compartir un hombre (poligamia) si lo han consentido sin recibir presiones. Son otros los desencadenantes fundamentales de su desigualdad, tales como el estatus de las mujeres en la legislación de familia, la desigualdad de oportunidades entre sexos en los ámbitos laboral y educativo, y la frecuente fiscalización social de casi todo cuanto hacen en el espacio público, factores que han tenido una incidencia parecida en algunas sociedades occidentales como la española hasta hace poco.

\section{Las dimensiones de la discriminación en el Magreb}

Como digo, son otros los factores que generan la discriminación de las magrebíes. A continuación esbozo su situación en los ámbitos jurídico, laboral y educativo. En el ámbito jurídico, las legislaciones familiares reflejan la desigualdad entre los sexos en cuanto a deberes y derechos asignados a cada uno. Existen destacables diferencias entre los Códigos de Familia magrebíes, como que en Túnez la poligamia y el repudio han sido abolidos, mientras en Argelia y Marruecos se mantienen. Sin embargo, las tres leyes mantienen la preeminencia del hombre sobre la mujer (Chater, 1992; Chamari, 1995; Ruiz, 1995).

En todas estas legislaciones la mujer tiene un estatus de eterna menor. Para casarse necesita un tutor (siempre varón) y para divorciarse necesita pruebas muy concretas y difíciles de aportar. Si obtiene una sentencia de divorcio vuelve a la tutela paterna, e incluso si dispone de recursos suficientes para tener una vivienda propia y sostener a sus hijos, no puede tomar sola las decisiones sobre éstos, requiriendo el consentimiento del ex-cónyuge. Además, si ésta vuelve a casarse pierde automáticamente la custodia de sus hijos. En contraste, el hombre no precisa tutor, como tampoco requiere evidencias para divorciarse, bastando con que manifieste su deseo de hacerlo y por último conserva el derecho de la custodia de sus hijos al desposar otra mujer (Moulay R'chid, 1991; Benmelha, 1993; Ruiz, 1995). Entre sus prerrogativas se encuentra también el que, como cabeza de familia, puede obligar a su esposa a abandonar su actividad laboral, acusándola de abandono de hogar cuando ella esté trabajando fuera de casa (Benmelha, 1993; Messaoudi, 1995).

Se pretende que estas leyes de familia están basadas en el Corán y la Charía ${ }^{10}$. En verdad, existen, sin embargo, diversas evidencias en la tradición musul-

11. La Charía, o ley islámica, es un conjunto de normas de comportamiento aconsejadas por reconocidos expertos en la religión musulmana para regir la sociedad y tiene su base en el Corán y los hadices, hechos y dichos del profeta y sus compañeros. 
mana que contradicen las disposiciones de estas leyes de familias. Casi siempre se trata de una pura tergiversación de la interpretación de los textos sagrados para justificar intereses parciales. De hecho existen varios ejemplos sobre la manipulación en la interpretación de algunos hadices por expertos en la religión (ulemas) para servir propósitos políticos y económicos. Los hadices son supuestos testimonios recogidos de lo que Mahoma hubiera dicho o hecho ante diversas cuestiones, y una vez aceptados como verosímiles, permiten fácilmente legitimar diversas conductas y proscribir otras. Probablemente, bajo las presiones de diversos poderes materiales, los depositarios del discurso religioso escogieron algunos hadices con sus propias interpretaciones tergiversadas que les permitieron legitimar ciertos privilegios y beneficiar a sus detentores (Delcroix, 1984; Bouhdiba, 1986; Mernissi, 1992; Benmelha, 1993).

Respecto al ámbito laboral, la participación de las magrebíes ha ido aumentando en función del desarrollo económico y la creciente necesidad de mano de obra. Hoy en día su incorporación al mercado laboral es una realidad, estando presentes en la mayor parte de los sectores productivos (Chater, 1992: 67; Bessis y Belhassen, 1994: 70-72; Ben Lahbib, 1995). No obstante, se trata de un incremento bastante pequeño que apenas reduce la diferencia con los hombres, y, además, es un fenómeno predominantemente urbano en Argelia y Túnez y particularmente rural en Marruecos. Asimismo, existen grandes diferencias entre países, ya que la tasa de participación femenina en la población activa de Argelia es mucho menor que la de Marruecos.

Por otra parte, aunque las circunstancias de muchas mujeres han mejorado y la educación ha sido esencial para ello, la mayoría continúa en situaciones desfavorecidas, empleadas sobre todo en el servicio doméstico, la industria manufacturera, la artesanal (en Túnez y Marruecos sobre todo en la textil) y en la administración pública (sobre todo en Argelia) (Benjelloun, 1993; Bessis y Belhassen, 1994). Es más, las pocas que ocupan puestos de prestigio siguen alejadas de tareas directivas. Las causas son diversas: reticencia a la contratación de mujeres; su escasa formación (sobre todo en Marruecos); una organización de la reproducción social que limita la vida laboral, y la percepción generalizada del trabajo femenino fuera del hogar como secundario.

También en el ámbito educativo han acontecido importantes cambios en el Magreb. Argelia y Túnez casi han alcanzado la equiparación entre sexos en la enseñanza primaria en cuanto a número de alumnos, pero persisten las diferencias en la secundaria y, muy especialmente, en la formación superior. Respecto a Marruecos, ni siquiera es capaz de asegurar una mínima igualdad en la instrucción infantil (véanse los datos de UNICEF, 1996: 90-91). Sin embargo, aunque la escuela es obligatoria y gratuita, las tasas de escolarización son más igualitarias en el medio urbano que en el rural, por las creencias que todavía conservan bastantes familias. Creencias que anteponen los varones a las hembras, atribuyendo a aquéllos el papel de sustento familiar y a éstas los de gestionar el hogar y criar la prole. Otros factores que obstaculizan la educación de las niñas son: la lejanía de la escuela (sobre todo las de la enseñanza secundaria, en muchos casos inexistentes), el coste de los materiales educativos, la inadapta- 
ción de los horarios escolares a la vida rural (para hacerlos compatibles con el trabajo de los niños, de difícil erradicación debido a la pobreza de las familias), la temprana edad matrimonial (Alaoui y otros, 1994) y el escaso interés estatal por asegurar la enseñanza obligatoria.

Estos factores, junto a otros como la escasa participación y representación política femenina, son manifestaciones muy importantes de la desigualdad de género. Aunque la emigración de las magrebíes suele entenderse, como la de sus homólogos masculinos, movida por razones económicas, la desigualdad de género ocupa también un lugar muy importante entre las razones de muchas emigrantes para instalarse en otra sociedad en la que creen que puede mejorar su estatus, derechos y autonomía, es decir, mujeres que emigran con objetivos emancipatorios (Ramírez, 1995; Ribas, 1996; Moualhi, en preparación).

\section{Conclusión}

Examinando el etnocentrismo occidental en la percepción de las mujeres árabo-musulmanas he querido demostrar que algunos de los estereotipos son falsos, basados sobre un imaginario lejano. Otros, sin embargo, tienen una base real, puesto que la poligamia y el uso del velo existen en todos los países musulmanes. Sin embargo, como estereotipos que son, tergiversan la realidad confundiendo la parte con el todo, obviando la diversidad sociocultural, éticoreligiosa y política existente en y entre los países árabes y/o musulmanes.

Dada la heterogeneidad del islam, con una pluralidad de escuelas teológicas, no se puede equiparar países tan diversos como la India, Indonesia, Marruecos, Irán y Yemen. Una pluralidad que también se da en su desarrollo jurídico incluso entre países con predominio de una misma escuela teológica. Por añadidura, incluso en un mismo país existen múltiples factores que hacen variar las situaciones, como son las diferencias de hábitat (rural-urbano), clase social, nivel de estudios, independencia económica, creencias familiares y generación, el funcionamiento del mercado de trabajo y las diversas políticas gubernamentales sobre los ámbitos laboral, familiar, educativo y cultural.

Parece que la construcción y difusión de estereotipos sobre los musulmanes guarda relación con las políticas internacionales y los procesos de identificación/diferenciación con la comunidad política. Desde los orígenes de la sociedad industrial, la construcción simbólica de la identificación con el sistema político, paradigmáticamente un Estado-nación, se fragua en buena parte por comparación y diferenciación respecto a un enemigo exterior. El temor a una agresión extranjera facilita la percepción de un interés compartido, mientras que si ese enemigo se esfuma se atribuye más importancia a los conflictos interiores y la identidad puede peligrar. Hobsbawm ha afirmado que "para unir a secciones dispares de pueblos inquietos no hay forma más eficaz que unirlos contra los de fuera» (1992: 100). Pues bien, en un escenario en el que el principal enemigo exterior tras la Segunda Guerra Mundial se ha desvanecido, el proceso de unificación europea y el mantenimiento de las estructuras militares parecen valerse de los fantasmas del islam para crear, de forma encubierta y 
apelando a la irracionalidad, una identidad común en la que apoyar las estructuras políticas supranacionales.

Quisiera subrayar que los estereotipos sobre la situación de las mujeres árabo-musulmanas son posiblemente el instrumento más eficaz para demonizar sus sociedades. No sólo consiguen escandalizar a gentes de convicciones cristianas al destacar las diferencias morales (no es casualidad que se obvien las muchas similitudes), sino que en una Europa muy secularizada logran sublevar a muchos ateos y a personas de orientación laica, neutral y tolerante respecto a las diferencias de credo, al ofrecer una imagen contraria al principio de la igualdad entre los seres humanos. Es decir, surte efecto tanto sobre personas de orientación conservadora como de orientación progresista.

Finalmente, si de verdad se quiere hacer un ejercicio de solidaridad con las mujeres inmigradas, debería comenzarse por sustituir la actitud de compasión y prejuicio por un ejercicio de receptividad e igualdad de trato. El hecho de haber emigrado es un claro signo de que no son pasivas ni sumisas, y sugiere también que su sociedad de origen está en un proceso de cambio, al aceptar e incluso apoyar en muchos casos la emigración de sus mujeres. Puesto que se trata de seres con autonomía e iniciativa, lo que cabría es escuchar y apoyar sus propias aspiraciones y demandas.

\section{Bibliografía}

Alaoui, Chérifa; Bakallil, N.; Boutata, M.; Chedati, B.; Kadmiri, B. (1994). Femmes et education, état des lieux. Casablanca: Le Fennec.

Benjelloun, Thérèse (1993). Femme, Culture, Entreprise au Maroc. Casablanca: Walada.

BENLAHBiB, Rafia (1995). «Mujer y cooperación intermagrebí». En MARTín MuÑoz, G. (comp.), obra citada.

BenMelHa, Ghaouti (1993). Le droit Algerien de la Famille. Alger: OPU.

Bessis, Sophie; BelHASSEN, S. (1994). Mujeres del Magreb. Lo que está en juego. Madrid: Horas y Horas.

BouHDiBA, Abdelwahab (1986). La sexualité en Islam [1975] París: PUF.

CorÁn, El (1994). España: M.E. [no consta el traductor, pero he cotejado los versículos con el original en árabe].

CHATER, Souad (1992). Les émancipées du Harem. Regard sur la famme tunicienne. París: La Press.

ChAmari, Alya Cherif (1995). «La Situación jurídica de la mujer en Túnez». En MarTín MuÑoz (comp.), obra citada, p. 37-47.

Delcroix, Catherine (1984). La situation de la femme arabe vue au travers de sa participation aux institutions politiques: étude comparée du cas de la citadine d'Alger et du Caire. Tesis doctoral. Bruselas: Universite Libre de Bruxelles.

DJEBAR, Assia (1992). «Mirada prohibida, sonido segado». Mientras tanto, 48. Barcelona.

DORKENDOO, Efua; ElWORTHY, Scilla (1994). Mutilació genital femenina: propostes per al canvi. Manchester: Minority Rights Group.

FANON, Franz (1972). L'an V de la Révolution algérienne [1959] [Reeditado bajo el título Sociologie d'une revolution. París: F.M./ Petite collection Maspéro].

HobSBAWM, Erik J. (1992). Naciones y nacionalismos desde 1780. Barcelona: Crítica. 
JANSEN, Willy (1989). «Ethnocentrism in the study of Algerian women». En AA.VV. History. Current issues in women's history. Londres: Routledge.

LERNER, Gerda (1990). La creación del patriarcado. [1986] Barcelona: Crítica.

LÜTZ, Helma (1991). "Migrant Women of "Islamic Background". Images and SelfImages». Middle East Research Associates. Occasional Paper n. 11.

MAALOUF, Amín (1994). Las cruzadas vistas por los árabes. [1983] Madrid: AlianzaEdiciones del Prado.

Martín Muñoz, Gema (comp.) (1995). Mujeres, democracia y desarrollo en el Magreb. Madrid: Fundación Pablo Iglesias.

MANYER I FARRÉ, Josep (1996). Quan L'Islam truca a la porta. [1992] Barcelona: Fundació Serveis de Cultura Popular-Altafulla.

MATEO DieSTE, Josep Lluis (1997). El «Moro» entre los primitivos. El caso del protectorado español en Marruecos. Barcelona: Fundación "La Caixa”.

MERNISSI, Fátima (1987). Le harem politique. Le prophéte et ses femmes. París: Albin Michel.

- (1992). El miedo a la modernidad. Madrid: Ed. del Oriente y del Mediterráneo.

MessaOudi, Jalida (1995). «El Código de la Familia en Argelia. Una decisión política». En MARTín MuÑoz (comp.), obra citada, p. 19-28.

Moulay R'CHID, Abderrazak (1991). La femme et la loi au Maroc. Casablanca: Le Fennec.

MOUALHI, Djaouida (1997). «Las migradas magrebíes en Cataluña (Área Metropolitana de Barcelona): El contexto de origen y las motivaciones de emigración». Tesina de Mágister, Universidad Autónoma de Barcelona.

- (en preparación) Dones magrebines a Catalunya: societat d'origen i motius d'emigració. Barcelona: Mediterrània.

MUJERES EN ACCIÓN (1993). «Mujeres mutiladas: ¿sólo una "tradición cultural”?». Isis internacional, 2.

NavArro, Josep Maria (ed.) (1997). El Islam en las aulas. Contenidos, silencios, ensenanza. Barcelona: Icaria y Antrazyt.

RAMírEZ, Ángeles (1995). «Las inmigrantes marroquíes en España. Emigración y emancipación». En MARTín MuÑOZ (comp.), obra citada.

- (1998). Migraciones, género e Islam. Mujeres Marroquies en España. Madrid: Agencia Española de Cooperación Internacional.

RamzI-Abadir, Sonia (1986). La femme arabe au Maghreb et au Machreck. Argel: ENAL.

RIBAS, Natalia (1996). «La heterogeneidad de la integración social. Una aplicación a la inmigración extracomunitaria (filipina, gambiana y marroquí) en Cataluña». Tesis doctoral. Bellaterra: Univesitat Autònoma de Barcelona.

ROBINSON, Francis (1990). El mundo islámico. Barcelona: Folio.

SANTAMARÍA, Enrique (1993). «(Re)presentación de una presencia. La "inmigración” en y a través de la prensa diaria». Archipiélago, núm. 12, p. 65-70, Barcelona. STOLCKE, Verena (1994). «Europa: Nuevas fronteras, nuevas retóricas de exclusión». En VV. AA, Extranjeros en el paraíso. Barcelona: Virus, p. 235-259.

TAARJI, Hinde (1991). Les voilées de l'Islam. Casablanca: EDDIF.

UNICEF (1997). La situation des enfants dans le monde 1996. Ginebra. 